\title{
Association of the PPP3CA c.249G >A variant with clinical outcomes of tacrolimus-based therapy in kidney transplant recipients
}

This article was published in the following Dove Press journal:

Pharmacogenomics and Personalized Medicine

31 March 2017

Number of times this article has been viewed

\author{
Patricia C Salgado' \\ Fabiana DV Genvigir' \\ Claudia R Felipe ${ }^{2}$ \\ Helio Tedesco-Silva J $\mathrm{r}^{2}$ \\ Jose O Medina-Pestana ${ }^{2}$ \\ Sonia Q Doi ${ }^{3}$ \\ Mario H Hirata' \\ Rosario DC Hirata' \\ 'Department of Clinical and \\ Toxicological Analysis, School of \\ Pharmaceutical Sciences, University \\ of Sao Paulo, ${ }^{2}$ Division of Nephrology, \\ Hospital do Rim, Federal University \\ of Sao Paulo, Sao Paulo, Brazil; ${ }^{3}$ School \\ of Medicine, Uniformed Services \\ University of the Health Sciences, \\ Bethesda, MD, USA
}

Background: The effects of genetic variants related to the pharmacodynamic mechanisms of immunosuppressive drugs on their therapeutic efficacy and safety have been poorly explored. This study was performed to investigate the influence of the $P P P 3 C A$ c. $249 \mathrm{G}>\mathrm{A}$ variant on the clinical outcomes of kidney transplant recipients.

Patients and methods: A total of 148 Brazilian patients received tacrolimus (TAC)-based immunosuppressive therapy for 90 days post-kidney transplantation. The PPP3CA rs3730251 (c.249G $>$ A) polymorphism was determined by real-time polymerase chain reaction. Singlenucleotide polymorphism (SNP) data for $C Y P 3 A 5$ rs776746 (CYP3A5*3C; g.6986A $>$ G) were used to eliminate the confounding effects of this variant.

Results: The PPP3CA c.249G >A SNP did not influence early TAC exposure, renal function, or other laboratory parameters, including levels of urea, creatinine, glucose, and lipids, and blood counts. This variant also did not account for the cumulative incidence of biopsy-confirmed acute rejection or delayed graft function. Regarding adverse events, PPP3CA c.249A allele carriers initially had a 3.05-fold increased probability of treatment-induced blood and lymphatic system disorders compared with c.249GG genotype individuals (95\% confidence interval: $1.10-8.48, \mathrm{p}=0.032$ ). However, this result was not maintained after adjusting for body weight and $C Y P 3 A 5 * 3 C$ SNP status $(\mathrm{p}=0.086)$.

Conclusion: The PPP $3 C A$ c. $249 \mathrm{G}>\mathrm{A}$ variant does not influence the clinical outcomes of Brazilian patients in the early phase of TAC-based immunosuppressive regimen.

Keywords: kidney transplantation, polymorphism, $P P P 3 C A$, tacrolimus, adverse events, Brazilian patients

\section{Introduction}

Pharmacogenetic approaches that focus on the pharmacodynamic mechanisms of drugs have the potential to increase the therapeutic efficacy and safety. ${ }^{1}$ For immunosuppressive drugs used in kidney transplantation, the effects of genetic variants related to these mechanisms on clinical outcomes have been poorly explored.

Tacrolimus (TAC) is an effective immunosuppressive agent. It can bind to FKBP12, and then this complex can bind to calcineurin, resulting in inhibition of the nuclear translocation of nuclear factor of activated T cells, and less activation of genes, including the one encoding interleukin-2 (IL-2). ${ }^{2,3}$ Consequently, both cytokine synthesis and $\mathrm{T}$ cell activation decrease. ${ }^{3}$

Calcineurin is $\mathrm{Ca}^{2+} /$ calmodulin-dependent serine/threonine phosphatase that is composed of catalytic $\mathrm{A}(\mathrm{CnA})$ and regulatory $\mathrm{B}$ subunits. ${ }^{4}$ For $\mathrm{CnA}$, three isoforms encoded by $P P P 3 C A(\mathrm{CnA} \alpha), P P P 3 C B(\mathrm{CnA} \beta)$, and $P P P 3 C C(\mathrm{CnA} \gamma)$ have been identified. ${ }^{5}$ Both
Correspondence: Fabiana DV Genvigir Department of Clinical and Toxicological Analysis, School of Pharmaceutical Sciences, University of Sao Paulo, Avenida Professor Lineu Prestes, 580, Bloco 17, 05508-900 Sao Paulo, SP, Brazil

Tel +55 II 30913660

Fax +55 II 38132197

Email fdallavecchia@yahoo.com.br 
the $\alpha$ and $\beta$ isoforms are ubiquitously expressed, whereas $\gamma$ is expressed in the testis and brain tissues. ${ }^{4,6}$

PPP3CA is located on human chromosome 4, and many single-nucleotide polymorphisms (SNPs) have been described at the PPP3CA locus. ${ }^{7,8}$ Several studies have explored the association of genetic variants at the $P P P 3 C A$ locus with physiological and pathological conditions, such as athletic status, susceptibility to addiction, and cardiac hypertrophy. ${ }^{5,9,10}$ However, to the best of our knowledge, only two studies have evaluated the association of the PPP $3 C A$ SNPs with the efficacy and toxicity of calcineurin inhibitors in renal transplantation. ${ }^{11,12}$

This study was designed to investigate the effect of the PPP3CA c.249G >A SNP on the clinical outcomes of TACbased immunosuppression in a prospective cohort of Brazilian patients in the early phase after kidney transplantation.

\section{Patients and methods}

\section{Patients and immunosuppressive regimens}

This investigation was performed with Brazilian adult recipients $(n=148)$ undergoing kidney transplantation for the first time and who had previously enrolled in a prospective core study, ${ }^{13}$ registered at ClinicalTrials.gov NCT01802268. The study protocol was approved by the institutional review boards of the School of Pharmaceutical Sciences, University of Sao Paulo, and the Federal University of Sao Paulo/Sao Paulo Hospital (Sao Paulo, Brazil). All subjects provided written informed consent before enrollment.

Within $48 \mathrm{~h}$ after the transplant surgery, all patients received TAC $(0.1-0.2 \mathrm{mg} / \mathrm{kg} /$ day $)$, enteric-coated mycophenolate sodium (MPS, initial fixed dose, $1440 \mathrm{mg} /$ day), and prednisone (initial dose, $0.5 \mathrm{mg} / \mathrm{kg} /$ day; maximum, $30 \mathrm{mg}$ with subsequent reduction to reach the maintenance dose of $5 \mathrm{mg} /$ day by day 45). The TAC dose was adjusted to maintain a blood concentration in the range of $8-15 \mathrm{ng} / \mathrm{mL}$ in the first month and $5-15 \mathrm{ng} / \mathrm{mL}$ during the second and third months of therapy.

\section{Therapy monitoring and laboratory tests}

Patients were followed for 3 months posttransplantation. Clinical outcome assessments included monitoring the following variables: episodes of the biopsy-confirmed acute rejection (BCAR, according to the Banff 1997 classification $^{14}$ ) and delayed graft function (DGF, defined as the use of dialysis within 7 days of the transplant), renal function, adverse events (AEs), and other clinical laboratory tests that were performed on blood samples that had been collected at every visit under fasting conditions (levels of urea, creatinine, glucose, and lipids, and blood counts).

Trough TAC concentrations in blood were determined by chemiluminescent microparticle immunoassay using ARCHITECT analyzers (Abbott Diagnostics, Abbott Park, IL, USA). The TAC dose-adjusted trough concentrations in blood $(\mathrm{C} / \mathrm{D}$ ratio; $\mathrm{ng} /(\mathrm{mL} \cdot \mathrm{mg}))$ were calculated. The estimated glomerular filtration rate (eGFR) was determined using the four-variable Modification of Diet in Renal Disease formula. ${ }^{15}$

AEs were defined as any untoward medical occurrence in a subject, with or without a causal relationship with drug treatment. ${ }^{16,17}$ All AEs were recorded and classified according to the System Organ Class of the Medical Dictionary for Regulatory Activities (MedDRA).${ }^{18}$ Duplication of AEs was not considered.

\section{Genomic DNA extraction and genotyping by real-time PCR}

Genomic DNA was extracted from pretransplant whole-blood samples using the QIAcube system (Qiagen, Hilden, Germany) and quantified using a Nanodrop ND-1000 instrument (NanoDrop Technologies, Wilmington, DE, USA). DNA integrity was evaluated using $0.8 \%$ agarose gel electrophoresis.

Subjects were genotyped for the $P P P 3 C A$ rs3730251 (c.249G $>\mathrm{A}$ ) and $C Y P 3 A 5$ rs776746 (CYP3A5*3C; g.6986A $>$ G) polymorphisms.

The SNP PPP3CA rs3730251 (c.249G>A) was selected for further investigation because it is present at the greatest global minor allele frequency among validated synonymous coding SNPs available from the Database of Single Nucleotide Polymorphisms (dbSNP) of the National Center for Biotechnology Information (NCBI). ${ }^{19}$ This variant was identified by real-time polymerase chain reaction (PCR), using a C_25618069_10 predesigned TaqMan ${ }^{\circledR}$ SNP genotyping assay (Thermo Fisher Scientific, Waltham, MA, USA). PCR amplification was carried out in a 7500 Fast Real-Time PCR thermocycler (Thermo Fisher Scientific) according to the manufacturer's instructions.

The SNP CYP3A5 rs776746 (CYP3A5*3C; g.6986A >G) was found to be the strongest predictor of TAC dosing requirements. ${ }^{20}$ Genotyping results for this variant were presented in a previous study. ${ }^{21}$

\section{Statistical analysis}

For pharmacogenetic analyses, individuals carrying the homozygous form of the less common allele (PPP3CA c.249A) were grouped with heterozygous carriers. 
Categorical variables were described as numbers and percentages and compared using the $\chi^{2}$ or Fisher's exact test. Estimates of Hardy-Weinberg Equilibrium (HWE) were also determined using the $\chi^{2}$ test.

Quantitative variables were expressed as mean \pm standard deviation. For two-group comparisons, Student's $t$-test (parametric) or Mann-Whitney test (nonparametric) was used. Stratification analyses based on $C Y P 3 A 5 * 3 C$ polymorphism were performed to eliminate the confounding effects of this variant on the results.

Logistic regression analysis was performed to assess the influence of the $P P P 3 C A \mathrm{c} .249 \mathrm{G}>\mathrm{A}$ polymorphism on the risk of AEs, BCAR, and DGF. The following covariates were considered: recipient body weight, TAC concentration, MPS and prednisone doses, and $C Y P 3 A 5^{*} 3 C$ SNP genotype. Multicollinearity was assessed based on two closely related statistics: the tolerance level $(>0.1)$ and variance inflation factor $(<10)$. Goodness of fit was assessed using the Hosmer-Lemeshow test; for this test, $p>0.05$ was regarded as satisfactory.

Statistical analyses were performed using GraphPad Prism $^{\circledR}$ (GraphPad Software, La Jolla, CA, USA) and SPSS for Windows (SPSS Inc., Chicago, IL, USA). Significance level was set at $p<0.05$.

\section{Results}

\section{Patients and PPP3CA c.249G>A SNP genotype}

The cohort of Brazilian kidney transplant recipients predominantly comprised young men (mean age, $45 \pm 13$ years; $69.6 \%$ ). The frequency of hypertension, diabetes, and dyslipidemia was $52.0 \%, 12.8 \%$, and $2.7 \%$, respectively (Table 1). The cumulative incidence rates of BCAR and DGF were $24.3 \%$ and $19.6 \%$, respectively. After 90 days of immunosuppressive therapy, the TAC blood concentration was $5.9 \pm 2.6 \mathrm{ng} / \mathrm{mL}$. In the same period, the MPS and prednisone doses administered were $1377.9 \pm 200.5$ and 5.6 \pm 3.0 $\mathrm{mg} /$ day, respectively (Table 1 ). The donors were mostly young women (mean age, $43 \pm 10$ years; $53.4 \%$ ). Living donor transplants represented the major type of transplantation (58.8\%; Table 1).

Genotype frequencies for the PPP3CA rs3730251 (c. $249 \mathrm{G}>\mathrm{A}$ ) variant were as follows: GG: $87.8 \%$, GA: $10.8 \%$, and AA: $1.4 \%$. This genotype distribution was in HWE. The frequency of the PPP $3 C A$ c.249A allele $(6.8 \%$, data not shown) was in accordance to that described by the 1000 Genomes Project (for all individuals). ${ }^{22}$

To obtain a more detailed analysis, anthropometric and clinical characteristics were evaluated in subgroups of the
Table I Biodemographical and clinical characteristics of Brazilian kidney transplant recipients and donors

\begin{tabular}{|c|c|}
\hline Variables & Patients, $n=148$ \\
\hline \multicolumn{2}{|l|}{ Recipients } \\
\hline Age (years) & $45.4 \pm 12.9$ \\
\hline Body weight (kg) & $66.3 \pm 12.6$ \\
\hline Sex, male & $103(69.6)$ \\
\hline \multicolumn{2}{|l|}{ Ethnicity } \\
\hline White & $69(46.6)$ \\
\hline Mixed & $53(35.8)$ \\
\hline African & $18(12.2)$ \\
\hline Others & $8(5.4)$ \\
\hline \multicolumn{2}{|l|}{ Comorbidities } \\
\hline Hypertension & $77(52.0)$ \\
\hline Diabetes & $19(12.8)$ \\
\hline Dyslipidemia & $4(2.7)$ \\
\hline Biopsy-confirmed acute rejection ${ }^{\mathrm{a}}$ & $36(24.3)$ \\
\hline Delayed graft function ${ }^{\mathrm{b}}$ & $29(19.6)$ \\
\hline \multicolumn{2}{|l|}{ Donors } \\
\hline Age (years) & $43.4 \pm 10.3$ \\
\hline Sex, male & $68(45.9)$ \\
\hline Missing data & $\mathrm{I}(0.7)$ \\
\hline Living donor & $87(58.8)$ \\
\hline \multicolumn{2}{|l|}{ Ethnicity } \\
\hline White & $82(55.4)$ \\
\hline Mixed & $46(31.1)$ \\
\hline African & $14(9.5)$ \\
\hline Others & $4(2.7)$ \\
\hline Missing data & $2(1.3)$ \\
\hline \multicolumn{2}{|l|}{ Immunosuppression at 90 days } \\
\hline Tacrolimus concentration $(\mathrm{ng} / \mathrm{mL})$ & $5.9 \pm 2.6$ \\
\hline Mycophenolate sodium dose (mg/day) & $1377.9 \pm 200.5$ \\
\hline Prednisone dose (mg/day) & $5.6 \pm 3.0$ \\
\hline
\end{tabular}

Notes: Values are represented as $n$ (\%). Age, body weight, and concentration and doses of the immunosuppressive drugs are presented as mean \pm standard deviation. ${ }^{a}$ Cumulative incidence. ${ }^{b}$ Defined as the use of dialysis within 7 days of the transplant.

patients based on the presence of the PPP $3 C A$ c. $249 \mathrm{G}>\mathrm{A}$ SNP. Age, type of transplantation, and frequencies of sex, ethnicity, comorbidities, BCAR, and DGF were similar between PPP $3 C A$ c.249A allele carriers (c.249GA+AA genotypes) and c.249GG genotype patients ( $p>0.05$, data not shown). However, $P P P 3 C A$ c.249GG patients had higher mean body weight $(67.1 \pm 12.5 \mathrm{~kg})$ than c.249A allele carriers $(59.7 \pm 11.4 \mathrm{~kg}, p=0.028)$.

\section{Associations among PPP3CA c.249G >A SNP, drug exposure, and treatment outcomes}

As expected, the PPP $3 C A$ c. $249 \mathrm{G}>$ A SNP did not influence either TAC exposure (dose, concentration, or $\mathrm{C} / \mathrm{D}$ ) or doses of MPS and prednisone administered during the study period (data not shown). Blood concentrations of TAC are strongly influenced by the $C Y P 3 A{ }^{*} 3 C \mathrm{SNP} ;{ }^{20}$ therefore, these data were also analyzed and compared after stratification based on this variant. No significant association was identified. 
Similarly, the PPP3CA c. $249 \mathrm{G}>\mathrm{A}$ polymorphism was not associated with differences in eGFR or other laboratory parameters, including levels of urea, creatinine, glucose, and lipids, and blood counts (data not shown).

Logistic regression analyses were performed to determine whether the $P P P 3 C A$ c. $249 \mathrm{G}>\mathrm{A}$ SNP could account for the cumulative incidence of BCAR, DGF, or AEs in this study (Table 2).

With regard to AEs, the PPP3CA c.249A allele carriers initially had a 3.05 -fold greater probability of treatmentinduced blood and lymphatic system disorders compared with c.249GG genotype patients (95\% confidence interval: 1.10 8.48, $p=0.032$; Table 2). However, this association was not

Table 2 Logistic regression analysis of association of PPP3CA c. $249 \mathrm{G}>\mathrm{A}$ polymorphism with clinical outcomes up to 90 days after kidney transplantation

\begin{tabular}{|c|c|c|c|c|}
\hline \multirow[t]{2}{*}{ Dependent variable } & \multicolumn{2}{|c|}{$\begin{array}{l}\text { Unadjusted logistic } \\
\text { regression }\end{array}$} & \multicolumn{2}{|c|}{$\begin{array}{l}\text { Adjusted logistic } \\
\text { regression }^{\mathrm{a}}\end{array}$} \\
\hline & OR $(95 \% \mathrm{CI})$ & $p$ & OR $(95 \% \mathrm{CI})$ & $p$ \\
\hline \multicolumn{5}{|l|}{ Adverse events } \\
\hline $\begin{array}{l}\text { Gastrointestinal } \\
\text { disorders }\end{array}$ & $\begin{array}{l}0.86 \\
(0.30-2.45)\end{array}$ & 0.773 & $\begin{array}{l}0.75 \\
(0.24-2.40)\end{array}$ & .630 \\
\hline Constipation & $\begin{array}{l}0.54 \\
(0.15-1.99)\end{array}$ & 0.357 & $\begin{array}{l}0.34 \\
(0.07-1.6 I)\end{array}$ & 0.172 \\
\hline D & $\begin{array}{l}0.90 \\
(0.30-2.69)\end{array}$ & 0.847 & $\begin{array}{l}1.08 \\
(0.34-3.38)\end{array}$ & .899 \\
\hline $\begin{array}{l}\text { Dyspeptic } \\
\text { syndrome }\end{array}$ & $\begin{array}{l}0.93 \\
(0.25-3.48)\end{array}$ & 0.915 & $\begin{array}{l}0.80 \\
(0.20-3.18)\end{array}$ & 75 \\
\hline $\begin{array}{l}\text { Nausea and/or } \\
\text { vomiting }\end{array}$ & $\begin{array}{l}0.89 \\
(0.19-4.24)\end{array}$ & 0.884 & $\begin{array}{l}0.42 \\
(0.05-3.54)\end{array}$ & 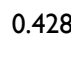 \\
\hline $\begin{array}{l}\text { Infections and } \\
\text { infestations }\end{array}$ & $\begin{array}{l}1.29 \\
(0.46-3.66)\end{array}$ & 0.631 & $\begin{array}{l}1.45 \\
(0.47-4.52)\end{array}$ & 5 \\
\hline $\begin{array}{l}\text { Metabolism and } \\
\text { nutrition disorders }\end{array}$ & $\begin{array}{l}1.00 \\
(0.33-3.02)\end{array}$ & 0.994 & $\begin{array}{l}I .3 \mid \\
(0.4 \mid-4.17)\end{array}$ & 645 \\
\hline $\begin{array}{l}\text { Nervous system } \\
\text { disorders }\end{array}$ & $\begin{array}{l}0.93 \\
(0.31-2.79)\end{array}$ & 0.899 & $\begin{array}{l}0.96 \\
(0.31-3.02)\end{array}$ & 0.945 \\
\hline & $\begin{array}{l}1.42 \\
(0.37-5.47)\end{array}$ & 0.606 & $\begin{array}{l}1.25 \\
(0.31-5.10)\end{array}$ & .756 \\
\hline $\begin{array}{l}\text { Renal and urinary } \\
\text { disorders }\end{array}$ & $\begin{array}{l}1.60 \\
(0.58-4.44)\end{array}$ & 0.367 & $\begin{array}{l}1.85 \\
(0.63-5.45)\end{array}$ & 0.267 \\
\hline $\begin{array}{l}\text { Blood and lymphatic } \\
\text { system disorders }\end{array}$ & $\begin{array}{l}3.05 \\
(1.10-8.48)\end{array}$ & 0.032 & $\begin{array}{l}2.66 \\
(0.87-8.13)\end{array}$ & 0.086 \\
\hline & $\begin{array}{l}2.92 \\
(0.98-8.72)\end{array}$ & 0.055 & $\begin{array}{l}2.42 \\
(0.70-8.29)\end{array}$ & .161 \\
\hline $\begin{array}{l}\text { Musculoskeletal and } \\
\text { connective tissue } \\
\text { disorders }\end{array}$ & $\begin{array}{l}I .33 \\
(0.40-4.41)\end{array}$ & 0.642 & $\begin{array}{l}1.27 \\
(0.36-4.48)\end{array}$ & 0.709 \\
\hline $\begin{array}{l}\text { Skin and subcutaneous } \\
\text { tissue disorders }\end{array}$ & $\begin{array}{l}0.32 \\
(0.04-2.57)\end{array}$ & 0.286 & $\begin{array}{l}0.40 \\
(0.05-3.25)\end{array}$ & 0.389 \\
\hline $\begin{array}{l}\text { Biopsy-confirmed acute } \\
\text { rejection }\end{array}$ & $\begin{array}{l}1.67 \\
(0.58-4.82)\end{array}$ & 0.346 & $\begin{array}{l}2.27 \\
(0.73-6.99)\end{array}$ & .154 \\
\hline Delayed graft function & $\begin{array}{l}1.70 \\
(0.55-5.22)\end{array}$ & 0.355 & $\begin{array}{l}1.27 \\
(0.37-4.40)\end{array}$ & .706 \\
\hline
\end{tabular}

Notes: Reference: PPP3CA c.249GG. ${ }^{2}$ Adjusted for body weight and CYP3A5*3C (rs776746) SNP status. Bold indicates significance.

Abbreviations: OR, odds ratio; $\mathrm{Cl}$, confidence interval; SNP, single nucleotide polymorphism. maintained after adjusting for body weight and $C Y P 3 A 5 * 3 C$ (rs776746) SNP status (Table 2). Adjustments for patient body weight were necessary because previous analyses had indicated that PPP3CA c.249GG patients were heavier than c.249A allele carriers. Moreover, an adjustment for TAC concentrations and doses of MPS and prednisone was performed. No significant result was detected (data not shown).

\section{Discussion}

Therapeutic drug monitoring (TDM) of TAC plays an important role in patient management. The goal of TDM is to use drug concentrations to manage the medication regimen of a patient and optimize clinical outcomes. ${ }^{23}$ However, the amount of drug measured in the blood does not accurately reflect its pharmacological effects. ${ }^{24}$

Biomarkers may be useful as they can quantitatively reflect the effects of a given drug on its target and also predict the clinical response to a drug. ${ }^{25}$ As the quantity of genetic data grows, genotyping will increasingly yield these useful biomarkers. ${ }^{26}$

This exploratory study was the first to investigate the effects of the PPP3CA c.249G $>$ A SNP on the efficacy and safety of a TAC-based regimen in Brazilian kidney transplant recipients who were followed for the first 3 months after transplantation. Moreover, it was the first investigation to evaluate the relationship of $P P P 3 C A$ polymorphisms with different classes of AEs. In this study, the $P P P 3 C A$ c. $249 \mathrm{G}>A$ SNP was not associated with risk of DGF, BCAR, or AEs. Moreover, this polymorphism was not associated with eGFR, biochemical blood tests, or early drug exposure in our patient cohort.

In accord with these findings, five other SNPs (rs13146281, rs7665292, rs2201677, rs10031159, and rs13117493) and one short tandem repetition (rs45441997) in PPP3CA were also not associated with risk of acute or subclinical rejection, or with serious infections in renal transplant recipients treated with calcineurin inhibitors. ${ }^{11,12}$ Similarly, variants in other genes that encode components of the calcineurin pathway, such as $F K B P 1 A$ (FKBP12), PPP3CB and PPP3R1 (calcineurin $\mathrm{B}, \alpha$ subunit), CALM1, 2, and 3 (calmodulin 1-3 isoforms), showed no association with the outcomes of treatment in renal patients..$^{11,12}$

We must note that these studies are in the preliminary stages; therefore, further investigations involving $P P P 3 C A$ polymorphisms and responses to therapy in kidney transplantation should be conducted. Indeed, until now, all of the studies had inherent limitations, including the sample size and number of genetic variants evaluated.

Noceti et $\mathrm{al}^{25}$ suggested a strong association between TAC pharmacodynamic parameters and polymorphisms in 
PPP3CA. The authors reported that, in ex vivo TAC-treated peripheral blood mononuclear cells from 35 volunteers, the PPP3CA rs45441997 variant was associated with variability in intracellular IL-2 expression in CD4 ${ }^{+} \mathrm{T}$ cells. ${ }^{25} \mathrm{IL}-2$, discovered as a $\mathrm{T}$ cell growth factor, is a cytokine produced after antigen activation that plays pivotal roles in the immune response. ${ }^{27}$ Its transcription can be inhibited by TAC. Studies involving IL2 polymorphisms have yielded encouraging results. The $I L 2$ rs2069763 and rs2069762 variants, for example, have been associated with acute rejection in Turkish and Brazilian kidney transplant recipients. ${ }^{28,29}$

\section{Conclusion}

The results reported here indicate that the $P P P 3 C A$ c. $249 \mathrm{G}>\mathrm{A}$ variant does not influence clinical outcomes in Brazilian patients who are in the early phase of TAC-based immunosuppressive regimen.

\section{Acknowledgments}

The authors thank Cristina M Fajardo, Vivian Bonezi, Antony BC Salazar, and Nagilla I Oliveira for technical support and assistance with patient enrollment. This work was supported by grants from FAPESP (project \# 2011/10039-6).

\section{Disclosure}

Fabiana DV Genvigir is a recipient of a fellowship (\#2014/18871-0) from FAPESP, Sao Paulo, Brazil. Mario H Hirata and Rosario DC Hirata are recipients of fellowships from CNPq, Brasilia, Brazil. The other authors report no conflicts of interest in this work.

\section{References}

1. Webster KD. Pharmacodynamics and pharmacogenomics. In: Zdanowicz MM, editor. Concepts in Pharmacogenomics. Bethesda, MD: American Society of Health-System Pharmacists; 2010:155-180.

2. Halloran PF. Immunosuppressive drugs for kidney transplantation. $N$ Engl J Med. 2004;351(26):2715-2729.

3. Lee RA, Gabardi S. Current trends in immunosuppressive therapies for renal transplant recipients. Am J Health Syst Pharm. 2012;69(22): 1961-1975.

4. Rusnak F, Mertz P. Calcineurin: form and function. Physiol Rev. 2000; 80(4):1483-1521.

5. He ZH, Hu Y, Li YC, et al. Are calcineurin genes associated with athletic status? A function, replication study. Med Sci Sports Exerc. 2011;43(8):1433-1440.

6. Cottrell JR, Li B, Kyung JW, et al. Calcineurin A $\gamma$ is a functional phosphatase that modulates synaptic vesicle endocytosis. J Biol Chem. 2016;291(4):1948-1956.

7. Wang MG, Yi H, Guerini D, Klee CB, McBride OW. Calcineurin A alpha (PPP3CA), calcineurin A beta (PPP3CB) and calcineurin B (PPP3R1) are located on human chromosomes 4, 10q21-->q22 and 2p16-->p15 respectively. Cytogenet Cell Genet. 1996;72(2-3): 236-241.
8. Pouché L, Stojanova J, Marquet P, Picard N. New challenges and promises in solid organ transplantation pharmacogenetics: the genetic variability of proteins involved in the pharmacodynamics of immunosuppressive drugs. Pharmacogenomics. 2016;17(3):277-296.

9. Chiocco MJ, Zhu X, Walther D, et al. Fine mapping of calcineurin (PPP3CA) gene reveals novel alternative splicing patterns, association of $5^{\prime} \mathrm{UTR}$ trinucleotide repeat with addiction vulnerability, and differential isoform expression in Alzheimer's disease. Subst Use Misuse. 2010;45(11):1809-1826.

10. Poirier O, Nicaud V, McDonagh T, et al. Polymorphisms of genes of the cardiac calcineurin pathway and cardiac hypertrophy. Eur J Hum Genet. 2003;11(9):659-664.

11. Moes DJ, Press RR, Ackaert O, et al. Exploring genetic and non-genetic risk factors for delayed graft function, acute and subclinical rejection in renal transplant recipients. Br J Clin Pharmacol. 2016;82(1):227-237.

12. Pouché L, Koitka M, Stojanova J, et al. A candidate gene approach of the calcineurin pathway to identify variants associated with clinical outcomes in renal transplantation. Pharmacogenomics. 2016;17(4):375-391.

13. Silva HT Jr, Felipe CR, Garcia VD, et al. Planned randomized conversion from tacrolimus to sirolimus-based immunosuppressive regimen in de novo kidney transplant recipients. Am J Transplant. 2013;13(12):3155-3163.

14. Racusen LC, Solez K, Colvin RB, et al. The Banff 97 working classification of renal allograft pathology. Kidney Int. 1999;55(2):713-723.

15. Levey AS, Bosch JP, Lewis JB, Greene T, Rogers N, Roth D. A more accurate method to estimate glomerular filtration rate from serum creatinine: a new prediction equation. Modification of Diet in Renal Disease Study Group. Ann Intern Med. 1999;130(6):461-470.

16. Felix MJ, Felipe CR, Tedesco-Silva H, Osmar Medina-Pestana J. Timedependent and immunosuppressive drug-associated adverse event profiles in de novo kidney transplant recipients converted from tacrolimus to sirolimus regimens. Pharmacotherapy. 2016;36(2):152-165.

17. Edwards IR, Aronson JK. Adverse drug reactions: definitions, diagnosis, and management. Lancet. 2000;356(9237):1255-1259.

18. MedDRA. Medical Dictionary for Regulatory Activities. Available from: http://www.meddra.org. Accessed January 4, 2016.

19. Database of Single Nucleotide Polymorphisms (dbSNP). Bethesda, MD: National Center for Biotechnology Information, National Library of Medicine. Available from: http://www.ncbi.nlm.nih.gov/SNP/. Accessed January 4, 2016.

20. Barbarino JM, Staatz CE, Venkataramanan R, Klein TE, Altman RB. PharmGKB summary: cyclosporine and tacrolimus pathways. Pharmacogenet Genomics. 2013;23(10):563-585.

21. Genvigir FD, Salgado PC, Felipe CR, et al. Influence of the CYP3A4/5 genetic score and $\mathrm{ABCB} 1$ polymorphisms on tacrolimus exposure and renal function in Brazilian kidney transplant patients. Pharmacogenet Genomics. 2016;26(10):462-472.

22. 1000 Genomes Project Consortium, Auton A, Brooks LD, Durbin RM, et al. A global reference for human genetic variation. Nature. 2015;526(7571):68-74.

23. Gross AS. Best practice in therapeutic drug monitoring. $\mathrm{Br} J$ Clin Pharmacol. 1998;46(2):95-99.

24. Capron A, Haufroid V, Wallemacq P. Intra-cellular immunosuppressive drugs monitoring: a step forward towards better therapeutic efficacy after organ transplantation? Pharmacol Res. 2016;111:610-618.

25. Noceti OM, Woillard JB, Boumediene A, et al. Tacrolimus pharmacodynamics and pharmacogenetics along the calcineurin pathway in human lymphocytes. Clin Chem. 2014;60(10):1336-1345.

26. Krejsa C, Rogge M, Sadee W. Protein therapeutics: new applications for pharmacogenetics. Nat Rev Drug Discov. 2006;5(6):507-521.

27. Liao W, Lin JX, Leonard WJ. Interleukin-2 at the crossroads of effector responses, tolerance, and immunotherapy. Immunity. 2013;38(1):13-25.

28. Seyhun Y, Mytilineos J, Turkmen A, et al. Influence of cytokine gene polymorphisms on graft rejection in Turkish patients with renal transplants from living related donors. Transplant Proc. 2012;44(5):1241-1249.

29. Morgun A, Shulzhenko N, Rampim GF, et al. Interleukin-2 gene polymorphism is associated with renal but not cardiac transplant outcome. Transplant Proc. 2003;35(4):1344-1345. 


\section{Publish your work in this journal}

Pharmacogenomics and Personalized Medicine is an international, peerreviewed, open access journal characterizing the influence of genotype on pharmacology leading to the development of personalized treatment programs and individualized drug selection for improved safety, efficacy and sustainability. This journal is indexed on the American Chemical
Society's Chemical Abstracts Service (CAS). The manuscript management system is completely online and includes a very quick and fair peer-review system, which is all easy to use. Visit http://www.dovepress. com/testimonials.php to read real quotes from published authors.

Submit your manuscript here: https://www.dovepress.com/pharmacogenomics-and-personalized-medicine-journal 